\title{
O VIRTUAL COMO IDEIA EM TRÂNSITO E O NOMADISMO DIGITAL PEDAGÓGICO COMO ATITUDE DOCENTE
}

\author{
EL VIRTUAL COMO IDEE EN TRÁNSITO Y EL \\ NOMADISMO DIGITAL PEDAGÓGICO COMO ACTITUD DOCENTE
}

\author{
THE VIRTUAL AS IDEA IN TRANSIT AND THE PEDAGOGICAL DIGITAL \\ NOMADISM AS A TEACHING ATTITUDE
}

Jaqueline Costa Castilho MOREIRA ${ }^{1}$

\begin{abstract}
RESUMO: Os "conceitos nômades" sugerem certas noções gerais que advém do intercâmbio entre os vários saberes. Este trabalho objetivou investigar como o termo "virtual" pôde ser aplicado pedagogicamente como conceito nômade, aprimorando práticas do currículo oficial paulista relacionadas à Educação Física, usando tecnologia disponível, leve e/ou de baixo custo. A metodologia utilizada nesta pesquisa educacional de abordagem qualitativa considerou uma revisão de literatura e um questionário aplicado como avaliação de uma formação continuada de trinta horas, ministrada a dez professores da rede pública que atuam na área no ano de 2016. Como resultado da concepção sugerida para os jogos virtuais, como jogos de representação com alguma tecnologia e que priorizam o movimento corporal e o compartilhamento de vivências, foi observado pelas respostas docentes, que esta acepção favoreceu $o$ entendimento de outras possibilidades de atuação docente pelos cursistas; instigou reflexões sobre as tecnologias disponíveis nas unidades escolares e as adaptações requeridas para o desenvolvimento da temática virtualização do corpo.
\end{abstract}

PALAVRAS-CHAVE: Conceito nômade. Jogos virtuais. Formação continuada. Educação física.

RESUMEN: Los "conceptos nómadas" sugieren ciertas nociones generales que provienen del intercambio entre los diversos saberes. Este trabajo objetivó investigar cómo el término "virtual" pudo ser aplicado pedagógicamente como concepto nómada, mejorando prácticas del currículo oficial paulista relacionadas a la Educación Física, usando tecnología disponible, ligera y/o de bajo costo. La metodología utilizada en esta investigación educativa de abordaje cualitativo consideró una revisión de literatura y un cuestionario aplicado como evaluación de una formación continuada de treinta horas, impartida a diez profesores de la red pública que actúan en el área en el año 2016. Como resultado de la concepción sugerida para los juegos virtuales, como juegos de representación con alguna tecnología y que priorizan el movimiento corporal y el compartir de vivencias, fue observado por las respuestas docentes, que esta acepción favoreció el entendimiento de otras posibilidades de actuación docente por los cursistas; instigó reflexiones sobre las tecnologías disponibles en las unidades

${ }^{1}$ Universidade Estadual Paulista (Unesp), Presidente Prudente - SP - Brasil. Professora Assistente Doutora do Departamento de Educação Física da FCT. E-mail: jackycastilho@fct.unesp.br.

RPGE - Revista on line de Política e Gestão Educacional, Araraquara, v.21, n.esp.3, p. 1668-1679, dez., 2017. 
escolares y las adaptaciones requeridas para el desarrollo de la temática de la virtualización del cuerpo.

PALABRAS-CLAVE: Concepto nómada. Juegos virtuales. Formación continuada. Educación física.

ABSTRACT: The "nomadic concepts" suggest certain general notions that come from the interchange between the various knowledges. This work aimed to investigate how the term "virtual" could be applied pedagogically as a nomadic concept, improving practices of the official São Paulo curriculum related to Physical Education, using available technology, light and/or low cost. The methodology used in this qualitative educational research considered a literature review and a questionnaire applied as an evaluation of a continuous training of thirty hours, given to ten teachers of the public schools that work in the area in the year 2016. As a result of the conception suggested for virtual games, such as games of representation with some technology and that prioritize the corporal movement and the sharing of experiences, was observed by the teachers answers, that this acceptance favored the understanding of other possibilities of teaching performance by the students; instigated reflections on the technologies available in the school units and the adaptations required for the development of the thematic virtualization of the body.

KEYWORDS: Nomad concept. Virtual games. Continuing education. Physical education.

\section{Introdução}

Os "conceitos nômades" sugerem certas noções gerais que advém do intercâmbio entre as várias faces das Ciências. Possibilitam outras formas de representação e organização do conhecimento por sua capacidade em transitar de uma disciplina a outra ou por aparecerem no perímetro de mais de um campo epistemológico. São transversais por migrarem de uma área a outra perturbando os territórios e aqueles que os detêm; subvertendo, conectando, desconectando e reconectando sentidos; incitando que infidelidades de concepção sejam cometidas; causando fluxos criativos que podem ampliar o conteúdo de um termo, ou mesmo originar um novo conhecimento. O termo "conceito nômade" foi cunhado por Stengers em 1988 e discutido por Brigitte Dumas (1999) em sua obra "Les savoirs nomades".

Dumas (1999) aponta uma relevante característica dos "conceitos nômades": a "elasticidade", a qual é apropriada por Mello, Domingos, Incrocci (2014) como resiliência. Para eles, ao enunciar a qualificação de um termo como "nômade", a flexibilidade tornar-se característica inerente, a qual deve ser suficientemente elástica

RPGE - Revista on line de Política e Gestão Educacional, Araraquara, v.21, n.esp.3, p. 1668-1679, dez., 2017. 
para transitar na estrutura de diferentes teorias, abarcando diversas áreas de saberes, sem perder sua essência conceitual.

Os "conceitos nômades" diferem da "polissemia" por ser uma expressão que apresenta diferentes significados ou sentidos; construídos a partir das relações entre diversos campos de saberes e/ou disciplinas, ou das distintas posições ocupadas pelos sujeitos que as utilizam e de suas afiliações. Segundo Cassiani, Linsingen e Giraldi (2011) outra característica divergente é de que a "polissemia" não é elástica, resiliente e transversal.

Dumas (1999) complementa essas reflexões afirmando que conceitos que perdem sua essência, objetivo e autonomia, apresentando vários significados em múltiplos contextos, são vertidos para o que é denominado por "polissemia". Na concepção da teórica, essa peculiaridade de alguns termos representa uma regressão da acepção de nomadismo.

O objetivo deste trabalho foi investigar como um conceito nômade aplicado pedagogicamente pode aprimorar práticas do currículo relacionadas à Educação Física com tecnologia disponível, leve ou de baixo custo.

\section{O virtual como conceito nômade}

O termo "virtual" é um forte candidato à categoria de conceito nômade. Para perscrutá-lo foi realizado um levantamento sobre sua acepção em várias áreas do conhecimento. A etimologia considera o termo originado do latim medievo virtualis, sugerido como uma possibilidade, algo que existe em potencial de algo ou que está em latência, com força e potência para ser, mas que "ainda não o é" (CRAIA, 2009).

$\mathrm{Na}$ atualidade e ainda no campo vernacular, o "virtual" significa "algo que equivale a outro, podendo fazer às vezes deste, em virtude ou atividade" (SOUZA, 2013, p. 01); ou na concepção anglo-saxônica apontada em Souza (2013, p.02): "algo que existe em essência ou efeito, embora não seja formalmente reconhecido e admitido como tal".

$\mathrm{Na}$ continuidade da discussão sobre o significado de "virtual" contribui significativamente o filósofo Deleuze (1996) que o diferencia do "possível”. Para ele, o "virtual” extrapola a ideia da "cristalização" (concretização) ou do "atualizar-se", que é um processo de resolução constante de situações ou de contínuas adequações ao 
presente: “[...] a imagem virtual não pára de tornar-se atual, como num espelho que se apossa do personagem, tragando-o e deixando-lhe, por sua vez apenas uma virtualidade (DELEUZE, 1996, p. 54)." Para o teórico, o virtual não se atualiza e nem se cristaliza, pois se assim o fizer abandonará sua essência de transitoriedade.

Complementa Levy (1996, p. 5), filósofo e pesquisador da cibernética, ao sugerir o virtual como "complexo problemático, o nó de tendências ou de forças que acompanha uma situação, um acontecimento, um objeto ou uma entidade qualquer, e que chama um processo de resolução, a atualização." O teórico assevera que o "virtual" não se opõem ao "real", mas a acepção do "atual"; pois enquanto o "real" assemelha-se ao possível, o "atual" em nada se parece com o "virtual", ele lhe responde. O "virtual" pertence a ordem do "terás" ou da ilusão, por ser "um processo de transformação de um modo de ser num outro" (LEVY, 1996, p. 3)

O estudioso insere termos derivados da noção original de "virtual" no desencadeamento de suas reflexões, desenvolvendo a ideia das "virtualizações" contemporâneas. A "virtualização do corpo" permite sua modelação a partir da biotecnologia; de implantes e próteses; de transplantes guiados por cirurgias remotas e da virtualização dos sentidos. Por meio dela é possível o compartilhamento do grande olho coletivo, ao sincronizar as pessoas nos mesmos programas de televisão, ou nas imagens no facebook, whatsapp, pinterest, entre outros; viabilizando sua integração dinâmica às sensações de outra pessoa, que se encontra em outro momento e lugar. "No reino do virtual, a análise e reconstrução do corpo não implica a dor, nem a morte" (LEVY, 1993, p. 15); pois sensores, scanners, ressonância, ecografia permeiam o corpo, reconstruindo-o de forma simulada para estudá-lo. Na perspectiva de uma finalidade hedônica, o hipercorpo criado não somente circula pela rede, como também é intensificado. O corpo virtualizado pode vivenciar esportes extremos ou mesmo esportes coletivos, estando sozinho frente a uma plataforma de jogo ou on line com jogos remotos; e sem dor ou risco de vida sua projeção (delegada a um avatar) favorece que (re) viva uma experiência sensorial/perceptiva quase completa.

As "virtualizações" reinventam o estilo de vida da cultura nômade, não por voltar ao passado dos povos coletores-caçadores; mas pela tecnologia oportunizar o rompimento de fronteiras com um mínimo de inércia, um clic, favorecendo o estabelecimento de interações sociais sem que haja qualquer deslocamento físico (LEVY, 1996; SILVA; MOREIRA, 2015). Quando uma pessoa, grupo, ato, informação se virtualiza, uma nova lógica se estabelece, tornam-se não presentes, se 
desterritorizam, havendo um desengate da unidade de lugar e tempo. A virtualização permite a multiplicação dos espaços, e segundo Levy (1996, p. 10) "faz de nós nômades de um novo estilo: em vez de seguirmos linhas de errância e de migração dentro de uma extensão dada: saltamos de uma rede a outra, de um sistema de proximidade ao seguinte". Enfim, as relações somente têm limites claros no real; na virtualização o privado e o público, o próprio e o comum, o subjetivo e o objetivo caminham em um constante devir (efeito Moebius). A virtualidade fluidifica as distinções instituídas ao colocar em causa a identidade clássica, o pensamento a partir de definições, tornando-se um processo de acolhimento da alteridade, promovendo a interatividade e a transição de uma inteligência coletiva para os coletivos inteligentes, que tendem a otimizar deliberadamente seus recursos do aqui e do agora.

Souza (2013), pesquisador com formação na Engenharia, em sua busca por uma definição comum e estrita para o termo "virtual" e "virtualidade", observa a incoerência das denominações encontradas na literatura, alertando para as dificuldades de se chegar a um consenso sobre a essência do termo. Para ele o "virtual" é algo "mediado ou potencializado pela tecnologia; produto da externalização de construções mentais em espaços de interação cibernéticos" (SOUZA, 2013, p. 8) e a "virtualidade" uma "qualidade de entidade que denota seu grau de extrapolação do concreto; ou grau de rompimento com as formas tradicionais de ser e acontecer. Usualmente associada às extensões tecnológicas" (SOUZA, 2013, p. 8).

O sucinto levantamento mostra a migração do "virtual" entre as áreas do conhecimento investigadas (a Engenharia, a Linguística, as Ciências Exatas, as da Saúde, as Sociais Aplicadas e as Ciências Humanas), além de sua presença na História. Os autores referem-se ao "virtual" a partir de expressões como latência ou potencial; transitoriedade; transformação; simulação; ruptura de limites; possibilidade de novas formas de relação social; todos eles viabilizados pela tecnologia. Assim, das acepções recuperadas para "virtual" exauriram três ideias: representação, tecnologia e interação; considerados como sua essência.

\section{O virtual na Educação Física}

A afluência entre o "virtual" e a "Educação Física" remete aos jogos virtuais. O videogame pioneiro foi Tennis Programing que surgiu em 1958. Em 1961, o jogo Spacewar, que apesar de simples teve grande aceitação como entretenimento. Na 
década de 1970 foram lançados os fliperamas; em 1972 os primeiros consoles e o Atari; em 1981 o Nintendo e, mesmo nessa progressão para atender o mercado promissor, entre 1983 e 1984 houve uma grande crise (BATISTA et al, 2007).

Devido aos empreendimentos tecnológicos por parte de multinacionais e medidas para conter a pirataria, houve uma rápida recuperação neste segmento, sendo disponibilizados além das inovações nos consoles, jogos para computadores, jogos on line, jogos para celulares. Algumas marcas apostaram em outro tipo de público, aquele que valoriza o movimento corporal. Esses jogos virtuais foram denominados de exergames, uma combinação entre jogos tecnológicos e exercícios físicos, que se popularizaram rapidamente pelo mercado de entretenimento (Nintendo Wii, XBOX Kinect/One, Playstation Move).

A tendência de virtualização do corpo também chegou aos ambientes educacionais tanto para os que desejam incorporar essas tecnologias como inovação, motivação e melhoria do ensino, como para aqueles que cumprem uma prescrição oficial. Embora a temática seja atual, as propostas de implementação representam um desafio aos professores, em especial aos que trabalham com a Educação Física na rede pública.

Há um consenso entre os autores (FERES NETO, 2005; VAGHETTI; BOTELHO, 2010; BARACHO; GRIPP; LIMA, 2012; FINCO; REATEGUI; ZARO, 2015; OLIVEIRA, MOREIRA; 2016) que a inserção da temática virtualidade em ambientes de Educação Básica tem sido acometida por uma série de fragilidades, tornando-a presente nos currículos apenas em discurso. Tem-se colocado em pauta vários obstáculos, dentre eles: a dificuldade de disponibilização de tecnologia aos envolvidos com o processo educacional para aprendizagem; o descompasso entre professores e alunos quanto à utilização das tecnologias; o hiato entre a teoria e a prática nos cursos de formação docente; no caso da Educação Física, a presença do estigma que correlaciona a virtualização do corpo ao sedentarismo, obesidade, hipocinestesismo, alienação, isolamento e depressão entre outros agravos; em relação às escolas públicas, são os obstáculos para se colocar em prática as propostas oficiais frente à infraestrutura e aos materiais e equipamentos existentes nas unidades e, para finalizar, nota-se ainda na contemporaneidade a existência de limitações da inserção de muitos jovens ao mundo digital por questões econômicas, políticas, sociais, culturais e cognitivas.

Aprofundando o debate sobre as questões econômicas e a inserção da tecnologia (especificada neste texto como o uso de jogos virtuais), observa-se no cotidiano 
brasileiro que ainda é recorrente sua associação com: tecnologias de ponta, altos custos financeiros e consequente restrição de acesso a uma grande camada da população e também ao ambiente escolar.

\section{Os jogos virtuais remodelados para a Educação Física}

Explicitado o panorama da virtualização do corpo na escola pública ficam os questionamentos de: como transpor os jogos virtuais de entretenimento em recursos com finalidade pedagógica dentro das aulas de educação física escolar? Como superar o delay tecnológico entre os professores e os alunos? Como viabilizar este conhecimento considerando as dificuldades de oferecimento deste tipo de jogo nas escolas públicas?

As respostas perpassam pela: seleção de jogos virtuais que envolvem movimento, que sejam adequados ao ambiente educacional e ao currículo oficial; pelo conhecimento e avaliação das condições de espaço físico, dos recursos e equipamentos oferecidos nas instituições e, pelas habilidades e competências dos professores em mediar criativamente essa problemática na escola e em compartilhar as vivências com os alunos.

No entanto, essa propositura somente se tornará possível se a concepção de virtual, ou de jogo virtual for revista. Pensando no virtual como conceito nômade, sua essência está na articulação entre representação, tecnologia e interação. Dessa forma, neste estudo, os jogos virtuais incorporam a ideia de serem jogos de representação e de envolverem amplos movimentos corporais (corpo todo) viabilizados por algum tipo de tecnologia e pelo compartilhamento de experiências.

Perscrutando cada uma das características, a primeira delas refere-se aos jogos virtuais como jogos de representação. Neste caso, jogos como Role Play Game (RPG) de Mesa podem ser acrescidos à seleção feita, desde que nas ações realizadas durante o jogo, haja movimentação corporal. Outros (também existentes no currículo oficial do Estado de São Paulo) como o Futebol de Botão com equipes de no mínimo dois jogadores e os Tapetes de Dança e o Twister também podem ser incluídos.

Como já mencionado, a movimentação corporal é característica fundamental para os jogos virtuais na Educação Física. Para atender esse requisito, os jogos tecnológicos que reconhecem os movimentos dos jogadores por meio de um sensor, os exergames, são relevantes como escolha. Em termos de plataformas específicas, o equipamento XBOX Kinect com os jogos Your shape; Nike; Kinect Sports Ultimate 
Collection; Kinect Adventure; Dance Central; Just Dance e suas várias versões podem fazer parte de uma programação pedagógica. Para minimizar os altos custos financeiros para aquisição de plataformas e a falta de recursos das unidades para sua compra, existem outras possibilidades, como salvar em formato de vídeo as coreografias dos jogos que se encontram disponibilizadas no Youtube para uso na televisão ou no datashow com equipamento de som; o Just Dance Now, que se utiliza de internet, de computador e do celular como sensor de movimento que oferece jogos gratuitos; os jogos de esporte do Interactive e os tapetes de dança do Play Step Mania e Dance Machine da Tec Toy.

A terceira característica remete a viabilização dos jogos virtuais tanto por meio das tecnologias disponíveis, leves ou de baixo custo como pela dupla-mão da imersão dos jogadores em ambientes virtuais, o que requer poucos recursos. Na perspectiva de tecnologias de baixo custo tem-se novamente o Interactive; os tabuleiros que podem ser confeccionados nas escolas como os de Dama/Xadrez humanos e o Twister adaptado ao uso de roletas disponibilizadas em aplicativos de celular. Algumas unidades, por iniciativa própria tem o Pebolim (Totó) como equipamento recreativo usado em intervalos e horário de almoço e que também é considerado um jogo virtual. As escolas da rede estadual paulista possuem uma Sala de Acesso a Informática (SAI) na qual há o "Acessa Escola" com vários softwares educativos, como a Torre de Hanoy, quebra cabeça que trabalha memória, planejamento e coordenação motora. Na perspectiva da imersão, além da inserção do jogador no ambiente virtual por meio de algum aparato tecnológico já apresentado acima; tem-se o processo inverso, ocasionado pela adaptação do mundo virtual a um contexto real, ainda pouco utilizado. Essa proposta pode ser realizada através de ambientação cenográfica/teatral e/ou por meio da imaginação ou representação mental de jogos existentes em plataformas de última geração. Por exemplo: os Webgames com o corpo (SCHWARTZ; TAVARES, 2015), novamente o Role Play Game (RPG) de Mesa com os dados disponibilizados em aplicativos, e os jogos de realidade aumentada como o Pikachu Go.

A última característica denominada de compartilhamento de experiências requisita dos docentes o "estar aberto a" aprender com os outros, reivindica que as armaduras sejam retiradas e que a postura defensiva em relação ao domínio de um território de saberes seja relevada (RAYNAUT, 2014). Enfim compartilhar é mais do que interagir ou integrar-se socialmente é trocar vivências com outros professores, com gestores, com os alunos, com pessoas de outras áreas do conhecimento. Entretanto, “o 
compartilhar" demanda do professor também que, "ao mesmo tempo" e "no momento certo", ele mobilize a especificidade de seus conhecimentos disciplinares, seu repertório de vida e de docência para que as mediações sejam voltadas não somente a um objetivo pedagógico determinado, como direcionado também ao bem estar do grupo. $\mathrm{O}$ compartilhar solicita do professor que esse momento pedagógico propicie avanço de um contexto de aprendizagem para outros e que os recursos existentes, do aqui e do agora da escola, possam ser otimizados por reflexões e ações conjuntas, interativas e compartilhadas.

\section{Metodologia}

Para trazer o conceitual para a prática, a metodologia utilizada nesta pesquisa educacional de abordagem qualitativa (MELLO, DOMINGOS, INCROCCI, 2014) considerou uma revisão de literatura acerca do virtual e dos jogos virtuais. Como este estudo acadêmico não faria sentido sem uma aproximação com os professores; em 2016 foi ministrada uma formação continuada de trinta horas aos docentes da Educação Física, ocorrida nas dependências da Diretoria de Ensino de Presidente Prudente/SP. Dez docentes de Ensino Fundamental e Médio, de ambos os gêneros, com idades entre 25-50 anos consentiram sua participação livre e esclarecida. Fazia parte do planejamento do curso que as dez aulas fossem divididas cada uma em três etapas: teórica, vivencial dos jogos virtuais, finalizando com o debate sobre a aplicação do jogo. Uma televisão, notebook, caixa de som, datashow, celular, games do XBOX Kinect (já mencionados no texto), jogo Interactive, materiais para Jogos de Botão, Tapetes de: Dança, Dama, Twister e Role Play Game (RPG) de Mesa foram os equipamentos evidenciados no curso. No encerramento da formação aplicou-se um questionário, com sete perguntas abertas para avaliação da formação. Destas, destacou-se neste estudo somente a que intencionava investigar se houve ou não efeitos do curso na prática docente em relação à temática curricular "virtualização do corpo".

\section{Resultados e discussão}

A seguir, a transcrição de algumas das respostas dos dez professores cursistas: 
Cursista 1: "Ao meu ver o curso expande os horizontes das práticas de atividade física na atualidade e aponta para várias situações onde podemos utilizar a tecnologia e novas formas de realizar algumas atividades, entretanto, existem pontos de nosso sistema educacional que precisam ser revistos para aderir a essa nova era tecnológica."

Cursista 3: "Algumas sugestões vou colocar em prática, relacionando sempre com o currículo oficial. Vou priorizar as atividades em que possa usar a SAI e os softwares educacionais e o recurso multimídia que possuo."

Cursista 5: "Faço uma análise positiva, pois após ter vivenciado os jogos virtuais e visto as várias opções afirmo que é possível desenvolver os jogos virtuais na sala de aula. Sendo que eu não sabia e nem conhecia muitos dos jogos e hoje a minha visão é outra. Também em relação aos materiais houve uma grande quantidade de sugestões nas atividades."

Cursista 7: "Foi muito bom para minha prática docente, pois, foi enriquecedor no conhecimento de novas práticas curriculares. E me mostrou que os jogos virtuais ficam bem além do XBOX".

Cursista 10: “Colocou em prática mais atividades que possam utilizar recursos tecnológicos disponíveis na Unidade Escolar com o objetivo de ajudar os alunos na assimilação de habilidades e competências."

A análise das transcrições evidenciou que o curso proporcionou a reflexão sobre estes jogos como recursos nas situações de aprendizagem para o desenvolvimento das atividades do currículo oficial. Por trabalhar com a essência do conceito de "virtual"; houve uma unanimidade nas respostas sobre o aproveitamento e a relevância do conteúdo da formação para o trabalho docente voltado não somente a temática da virtualização do corpo, mas usando os jogos virtuais como simuladores lúdicos de vivências em situações de aprendizagem de esportes; os quais as escolas nem sempre oferecem materiais e equipamentos para a prática. Exemplificando alguns deles: o boxe, o tênis de mesa, o futebol americano, e as modalidades do atletismo.

Esse resultado difere de outros estudos que apontam a tensão ocasionada pelas tecnologias à disposição dos jovens como jogos e aplicativos, inclusive por meio dos celulares; a precariedade do acesso à tecnologia em contextos educacionais; a ausência de recursos financeiros para a compra de plataformas (FERES NETO, 2005; BARACHO; GRIPP; LIMA, 2012). Acrescenta-se ainda, a necessidade nem sempre 
suprida de formar professores que saibam utilizar tecnologias que permitam interação e compartilhamento.

\section{Considerações finais}

No âmbito educacional, o "virtual” perturba ideias postas e as práticas escolares existentes, subvertendo, conectando, desconectando e reconectando sentidos. Por sua elasticidade, resiliência, transversalidade e autonomia, o "virtual" assim como outros conceitos nômades, aparece nas regiões limítrofes dos variados territórios de estudos, o que no caso da Educação Física escolar contribuiu para outro ordenamento prático e metodológico.

A concepção sugerida para os jogos virtuais favoreceu o entendimento de outras possibilidades de atuação docente; instigou reflexões sobre as tecnologias disponíveis nas unidades e as adaptações requeridas para o desenvolvimento da virtualização do corpo. Das discussões sobre as potencialidades e as fragilidades desses jogos no ensino formal, emergiram como os professores se sentem perante o domínio que os jovens têm da tecnologia.

E para minimizar a dificuldade explicitada pelos docentes retomou-se a ideia de nomadismo de Levy (1996). O nomadismo digital pedagógico é uma atitude itinerante que o professor pode tomar frente ao delay tecnológico, sem se sentir inferiorizado ou inadequado. Transitar entre as tecnologias com mobilidade para usar o conhecimento específico que detêm, acrescido do repertório de vida e de docência possibilitam romper fronteiras e preconceitos. Essa será uma atitude requerida não somente aos professores, pois toda a tecnologia do hoje se tornará obsoleta em poucos anos e independentemente de qual faixa etária se encaixe, haverá a necessidade do deslocamento da zona de conforto para o "aprender" migrando.

AGRADECIMENTOS: A Secretaria de Educação do Estado de São Paulo por meio da Diretoria de Ensino da Região de Presidente Prudente e de seus representantes dos Núcleos Pedagógicos de Educação Física e de Informática; ao Núcleo de Pesquisa/PROGRAD/UNESP; aos Bolsistas do Núcleo e Graduandos Voluntários do Grupo de Estudos e Pesquisa "Inovações Pedagógicas, Tecnológicas e suas Histórias"/IPTECHI e aos Professores estaduais participantes. 


\section{REFERÊNCIAS}

BARACHO, A. F. O.; GRIPP, F. J.; LIMA, M. R. Os exergames e a educação física escolar na cultura digital. 2012. Disponível em: 〈http://goo.gl/FRBcZF>. Acesso em: 12 jun. 2014.

BATISTA, M. L. S. et al. Um estudo sobre a história dos jogos eletrônicos. 2007. Disponível em: <http://re.granbery.edu.br/artigos/MjQ4.pdf>. Acesso em: 12 set. 2016.

CASSIANI, S.; LINSINGEN, I. V.; GIRALDI, P. M. História de Leituras: produzindo sentidos sobre Ciência e Tecnologia. Pro-Posições, Campinas, v. 22, n. 1, p. 59-70, jan./abr. 2011.

CRAIA, E. O virtual: destino da ontologia de Gilles Deleuze. 2009. Disponível em: <http://www.repositorio.unicamp.br/bitstream/REPOSIP/72646/1/WOS0002708101000 09.pdf>. Acesso em: 20 nov. 2016.

DELEUZE, G. O atual e o virtual. 1996. Disponível em:

$<$ https://antropologiassociativa.files.wordpress.com/2010/06/deleuze_1996_o-atual-e-ovirtual_bookchapt.pdf>. Acesso em: 20 nov. 2016.

DUMAS, B. Les savoirs nomade. 1999. Disponível em: < http://id.erudit.org/revue/socsoc/1999/v31/n1/001214ar.html?lang=en>. Acesso em: 17 nov. 2014.

FERES NETO, A. Videogame e Educação Física/Ciências do Esporte: uma abordagem à luz das teorias sobre o virtual. 2005. Disponível em:

<http://www.efdeportes.com/efd88/video.htm>. Acesso em: 12 jun. 2014.

FINCO, M. D.; REATEGUI, E. B.; ZARO, M. A. Laboratório de Exergames: Um Espaço Complementar para as Aulas de Educação Física. Movimento: Rev. Esc. Ed. Fís., UFRGS, Porto Alegre, v. 21, n. 3, p.687-699, 2015.

LÉVY, P. O que é virtual. São Paulo: Editora 34; 1996.

MELLO, A. S.; DOMINGOS, B. S. M.; INCROCCI, L. O processo de construção de uma pesquisa interdisciplinar: simetria e conceitos nômades. 2014. Disponível em: <www.rbgdr.net/revista/index.php/rbgdr/article/download/1470/393>. Acesso em: 17 nov. 2014.

RAYNAUT, C. A questão interdisciplinar/vídeo. 2014. Disponível em: <https://www.youtube.com/watch?v=DrBNs3gCoss>. Acesso em: 24 nov. 2014.

SCHWARTZ, G. M.; TAVARES, G. H. (Orgs.) Webgames com o corpo. São Paulo: Ed. Phorte, 2015.

SOUZA, R. R. O que é realmente o virtual? 2013. Disponível em: $<$ http://www.ccuec.unicamp.br/revista/infotec/artigos/renato.html $>$. Acesso em: 20 nov. 2016.

RPGE - Revista on line de Política e Gestão Educacional, Araraquara, v.21, n.esp.3, p. 1668-1679, dez., 2017. 
VAGHETTI, C. A. O.; BOTELHO, S. S. C. Ambientes virtuais de aprendizagem na Educação Física. 2010. Disponível em: 〈http://goo.gl/4XPnGy>. Acesso em: 12 jun. 2014.

\section{Como referenciar este artigo}

MOREIRA, Jaqueline Costa Castilho. O virtual como ideia em trânsito e o nomadismo digital pedagógico como atitude docente (Brasil). Revista on line de Política e Gestão Educacional, Araraquara, v.21, n.esp.3, p. 1668-1679, dez., 2017. ISSN: 1519-9029.

Submetido em: 20/03/2017

Aprovado em: 07/07/2017 